\title{
Demand and Energy
} Characteristics of NonResidential Alternating Current Level 2 Electric Vehicle Supply

\section{Equipment}

Idaho National Laboratory

June 2015

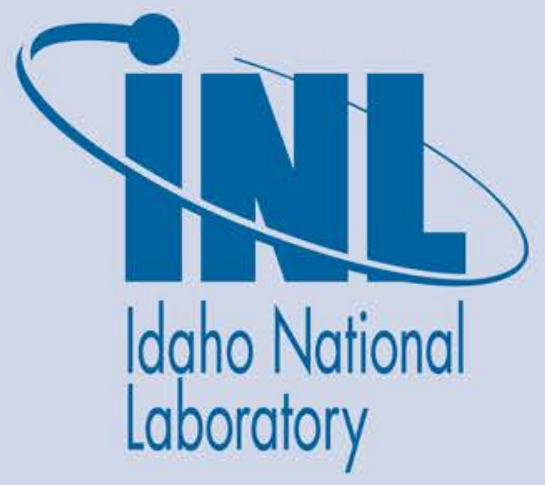

The INL is a U.S. Department of Energy National Laboratory operated by Battelle Energy Alliance 
INL/EXT-15-36765

\section{Demand and Energy \\ Characteristics of Non-Residential Alternating Current Level 2 Electric Vehicle Supply Equipment}

Idaho National Laboratory

June 2015

Idaho National Laboratory
Idaho Falls, Idaho 83415

http://www.inl.gov

Prepared for the

U.S. Department of Energy

Assistant Secretary for _ , OR Office of

Under DOE Idaho Operations Office

Contract DE-AC07-05ID14517 


\section{Demand and Energy}

Characteristics of Non-Residential Alternating Current Level 2 Electric Vehicle Supply Equipment

June 2015

\section{Key Conclusions}

- The EV Project vehicle data show that approximately $14 \%$ of Chevrolet Volt charge events occurred away from home and approximately $20 \%$ of Nissan Leaf charge events occurred away from home.

- The EV Project vehicle data show that geographic regions can plan that the total number of non-residential charge events in a calendar quarter will be approximately 5.3 times the number of plug-in electric vehicles (PEVs) in the region.

- The EV Project vehicle data show that geographic regions can plan charging at publicly accessible alternating current (AC) Level 2 electric vehicle supply equipment (EVSE) in the region will occur predominately between 8 a.m. and 2 p.m. at a median peak demand of $0.1 \mathrm{~kW}$ times the number of PEVs in the region.

- The EV Project vehicle data show that the average connect time at a publicly accessible AC Level 2 EVSE is approximately 3 hours. During this time, the average energy consumed by the PEV is $9.1 \mathrm{kWh}$.

- The EV Project vehicle data show that the average connect time at AC Level 2 EVSE operated in fleet applications is approximately $73 / 4$ hours. During this time, the average energy consumed by the PEV is $12 \mathrm{kWh}$.

\section{Introduction}

Because the power required to recharge a PEV can be a significant additional electrical load for the charging site host and can contribute to overall load on the electric grid, a frequently asked question related to adoption of PEVS is, "What is the impact of PEV charging on the electrical grid?" This question can be directed at the big picture of total utility system load or at the impact to the local business hosting the EVSE. The local effects to the business owner for clustering of non-residential charging PEVs were addressed in Characterize Clustering of Commercial Alternating Current Level 2 Electric Vehicle Supply Equipment, ${ }^{1}$ and the effects on utility demand charges were addressed in What is the Impact of Utility Demand Charges on the Alternating Current Level 2 Host?. ${ }^{2}$ The focus of this paper is on the impact of PEV charging on total system load and identification of the distinguishing features of a typical non-residential AC Level 2 EVSE charge, including its charge profile (i.e., load duration curve).

\section{Data Analyzed}

The EVSE deployed by The EV Project included both residential and non-residential units. Approximately 4,000 non-residential AC Level 2 EVSE were installed in workplace environments, fleet applications, and publicly accessible locations near retail centers, parking lots, and similar venues. Use of these EVSE is analyzed in this paper using reports published by The EV Project on a quarterly basis, aggregating specific charging data for that quarter and the project to-date. Electric utilities within the boundaries of The EV Project specifically requested information related to demand and energy requirements for charging of PEVs be included in these reports. All reports are available at avt.inl.gov/evproject.shtml. Data collected through internet communications with the Blink AC Level 2 EVSE installed in non-residential locations were also utilized.

Analyzed data points included regional median power demand, number of EV Project participants, energy consumed, time connected, percentage of vehicle charging away from home, and energy consumed per charging event. These data points are available for both weekday and weekend time periods; however, weekday time periods were used for this paper.

The charge rate and, therefore, the power demanded for PEV charging are determined by the PEVs' onboard battery management systems. The Blink AC Level 2 EVSE provided to The EV Project's charging site host is rated to continuously deliver up to $7.2-\mathrm{kW}$ power to a connected PEV. The EV Project charge data show that most PEVs participating in The EV Project charged at $3.76 \mathrm{~kW}$ or less, with a much smaller number of vehicles charging at up to a peak of $7.4 \mathrm{~kW}$.

\section{Utilization}

To determine the utilization of non-residential EVSE, a correlation between the number of charging events in a locale with the population of PEVs in that locale was performed. Data collected by The EV Project allowed correlation of PEVs enrolled in the project with their charging at residential and non-residential EVSE. However, the non-residential EVSE were also available for use by PEVs not enrolled in The EV Project. Data from non-EV Project vehicles in each region are not available for analysis. Thus, analysis of EVSE usage involved more than vehicles enrolled in The EV Project. 
In addition, not all PEVs are charged away from home. The report titled, Characterize Plug-In Electric Vehicle Driver Away-From-Home Parking Behavior in San Diego ${ }^{3}$ identified that 32\% of PEV drivers in The EV Project in San Diego never charged away from home during the last half of 2013. However, if away-from-home charging behavior is consistent among the regions on a large scale, a correlation between away-from-home charge events and numbers of PEVs can be made.

The EV Project's quarterly reports provide charging information for The EV Project vehicles (i.e., the Chevrolet Volt and Nissan Leaf). Data collected and aggregated by The EV Project identify charging events that occur at the PEVs home location and away from home. Figures 1 and 2 show the percentage of vehicle charge events that were away from home for the Chevrolet Volt and Nissan Leaf in The EV Project by quarter for 2013 in each region of The EV Project.

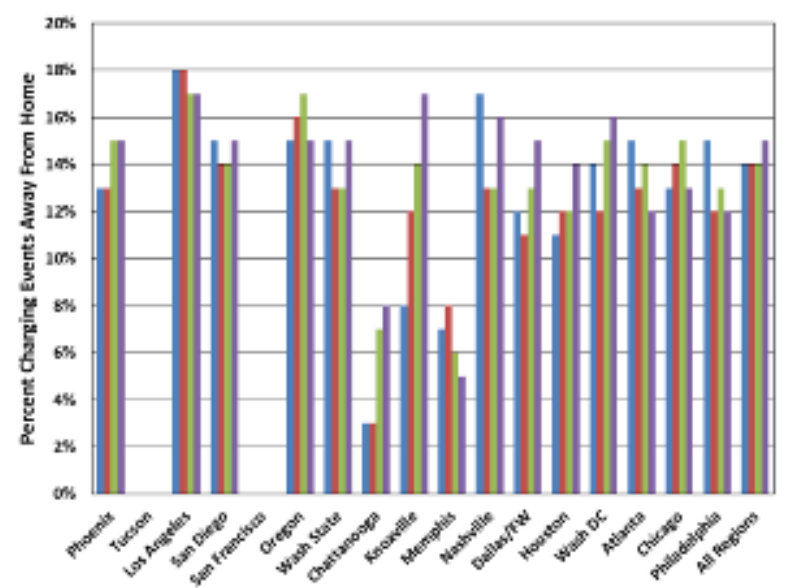

Figure 1. Volt away-from-home charging quarters one through four of 2013.

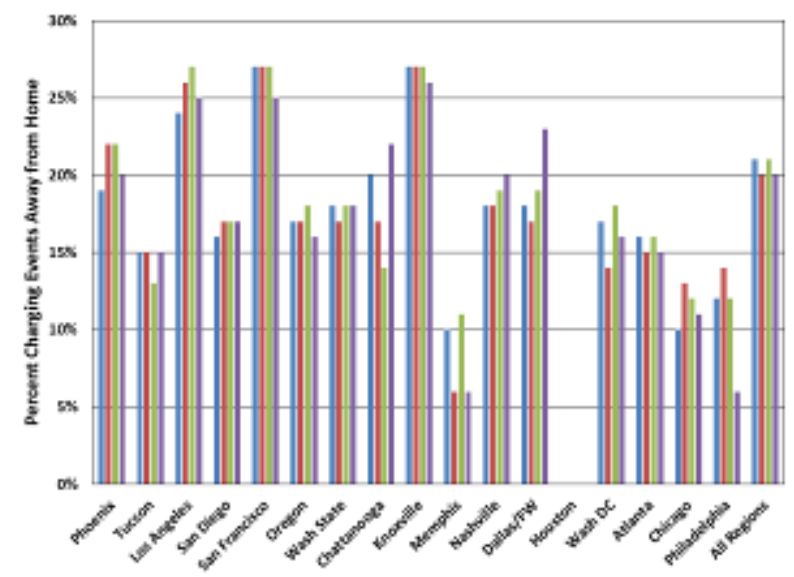

Figure 2. Leaf away-from-home charging quarters one through four of 2013.

While there were variations between regions, each region was fairly consistent with the percent of charging that occurred away-from-home. The far right columns for "All Regions" show very consistent percentages for all quarters of 2013 . On average, $14 \%$ of Volt charging and $20 \%$ of Leaf charging was conducted away from home. These two vehicles had the highest cumulative U.S. sales volumes among PEVs throughout the analysis period. ${ }^{4}$

The consistency for each of these regions suggests consistency for all regions where PEVs are available and sufficient away-from-home charging is available.

\section{Demand Effects}

Charging demand is defined as the total amount of power being drawn from the electric grid for the purpose of charging PEVs. This is calculated by aggregating charge data generated from metering in all Blink EVSE in the area of interest over the timeframe desired. In Figures 5 and 6 , demand for each day of the quarter is overlaid on the time of day; therefore, the upper blue line indicates maximum demand, the red line shows minimum demand, and the black line shows median demand over the quarter. The inner quartiles are shown as gray shaded areas. Data for weekdays and weekends are graphed separately. The following analysis uses the weekday median values for electrical demand.

\section{Publicly Accessible Electric Vehicle Supply Equipment}

Figure 3 shows the aggregated charging demand for all publicly accessible EVSE in The EV Project during the fourth quarter of 2013.

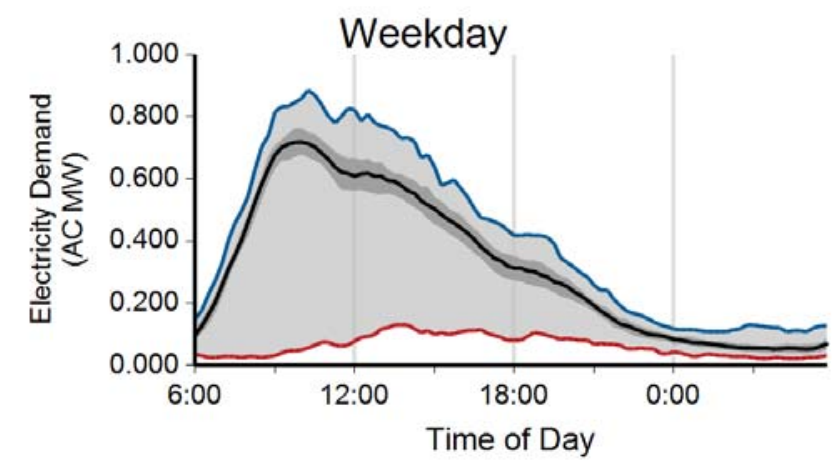

Figure 3. Aggregated publicly accessible charging demand for all regions in The EV Project during the fourth quarter of 2013.

In Figure 3, the median value and inner quartile regions are closely grouped, indicating close agreement between regions for these times of the day.

Aggregated data for all regions of The EV Project do not identify some of the specific characteristics of the individual regions. In fact, the quarterly reports show specific deviations from the all-region graphs. For example, the 
Atlanta region experienced the demand shown in Figure 4 during the fourth quarter of 2013.

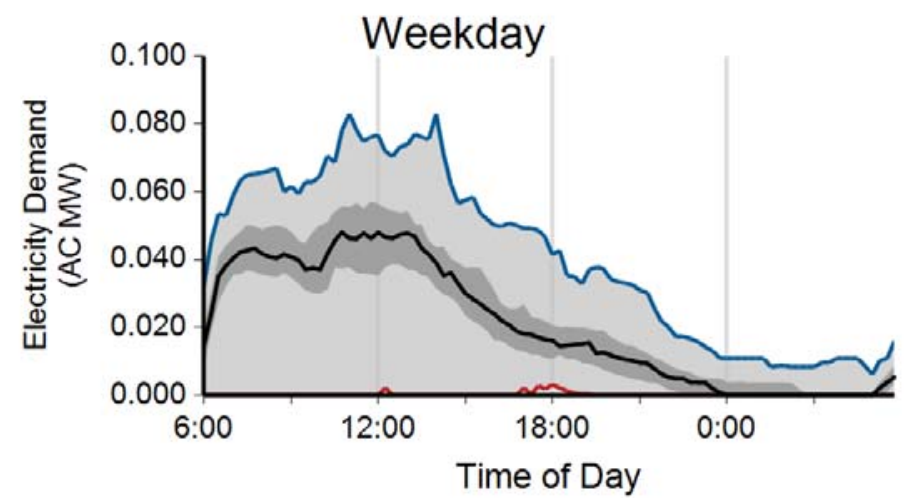

Figure 4. Weekday publicly accessible charging demand in Atlanta during the fourth quarter of 2013.

This "twin peak" characteristic of median demand may cause the daily highest peak to shift from morning to afternoon in various quarters.

Five regions of The EV Project were selected for comparison to the all-region data: Atlanta, Los Angeles, Oregon, Phoenix, and San Diego. The peak time in median electricity demand is shown in Figure 5 . Oregon and San Diego display the shift in peaks between mornings and afternoons.

While the time of peak use of publicly accessible EVSE varies, the overall highest usage times are consistently between 8 a.m. and 2 p.m. daily.

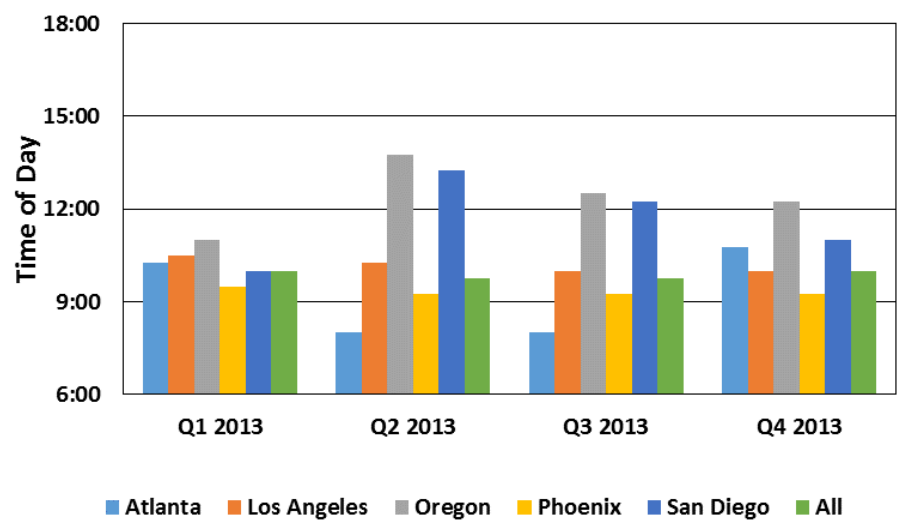

Figure 5. Time of peak median power demand for publicly accessible EVSE in 2013.

Supermarkets are popular charging site hosts for publicly accessible EVSE. The load profile for a typical supermarket in the Phoenix area during the summer months is shown in Figure 6.

The average time of peak usage of publicly accessible EVSE typically occurs before the peak demand of the charging site host's normal electrical demand; therefore, the demand curve of Figure 6 shows significant demand through the peak of the host. In addition, Reference 2 identifies cases of public charging coincident with the business peak

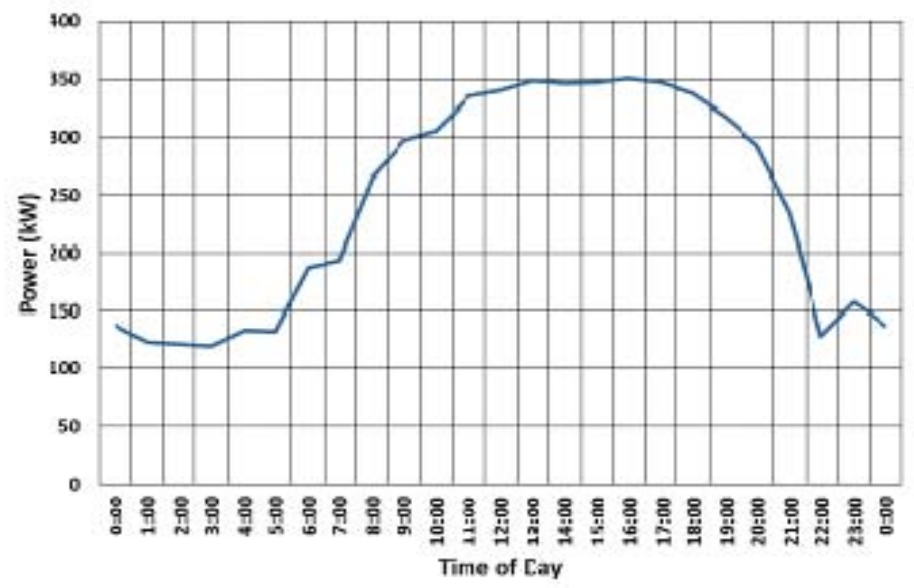

Figure 6. Typical supermarket daily load profile in Phoenix during the summer."

Because there appears to be some correlation between the number of charging events away from home and the number of PEVs in a region, an investigation to quantify the expected highest median demand in a region based on PEV population in that region can be made.

The highest median demand in each region is divided by the number of EV Project vehicles in each region. The highest, lowest, and average values over all regions with more than 100 PEVs enrolled is shown in Figure 7 by quarter.

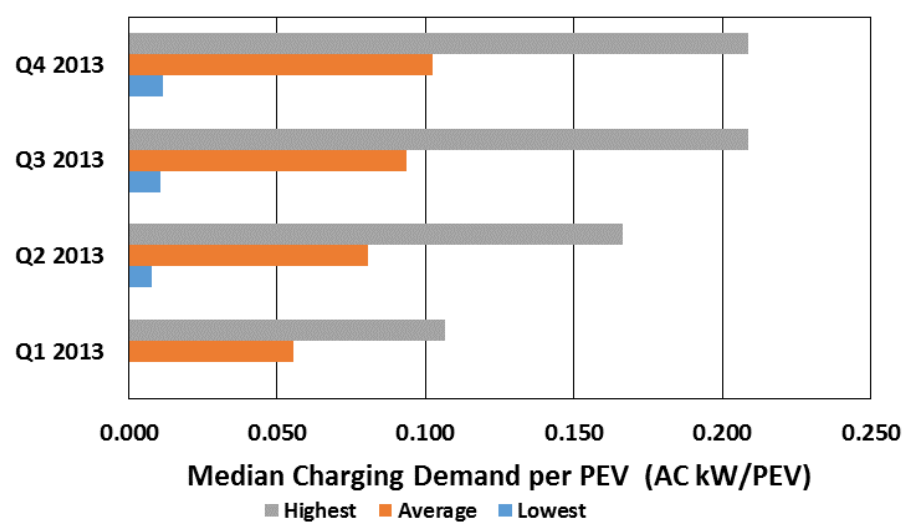

Figure 7. Median demand of publicly accessible EVSE per PEV in The EV Project.

Because of The EV Project data aggregation rules, some regions did not report demand; therefore, the lowest in one quarter is zero. In the fourth quarter of 2013 , the average for all regions was approximately $0.1 \mathrm{~kW}$ per PEV. Similar to estimating purposes, the peak median demand would be expected to occur between 8 a.m. and 2 p.m. at a level of 
approximately $0.1 \mathrm{~kW}$ times the number of PEVs in the region.

For the charging site host, peak demand would be expected to be between 8 a.m. and 2 p.m. at $3.76 \mathrm{~kW}$ (or $7.2 \mathrm{~kW}$ for later model PEVs) times the number of EVSE on site for sites with only a few EVSE. For sites with a large number of EVSE, both the peak demand and the time of peak demand may vary.

\section{Private Non-Residential Electric Vehicle Supply Equipment}

Considering all private non-residential charging, Figure 8 shows the aggregated charging demand for all regions of The EV Project in the fourth quarter of 2013.

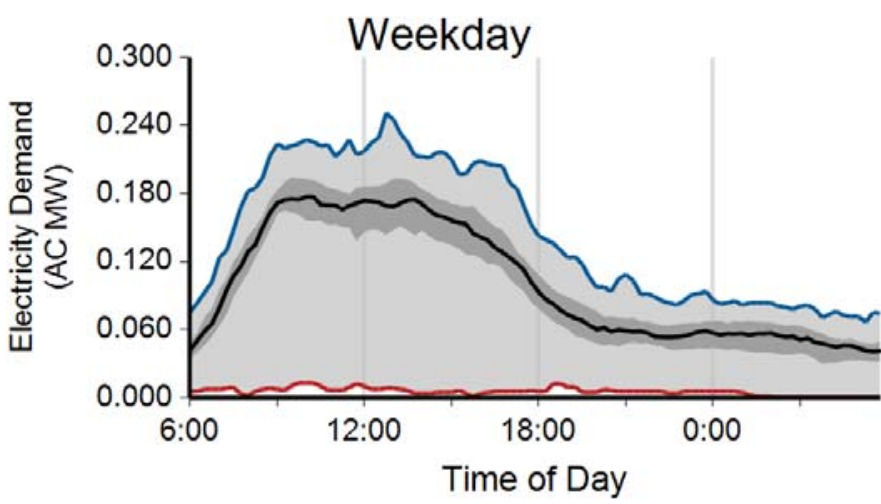

Figure 8. Aggregated private non-residential charging demand for all regions of The EV Project during the fourth quarter of 2013.

Private non-residential EVSE include fleets and workplace EVSE. The comparison of times of peak median demand for each of the five regions identified above is shown in Figure 9.

Utilization is very dependent on fleet operation or the workplace charging strategy; generalizations on peak demand times or its magnitude are not possible. Fleets and workplace owners would likely be aware of their normal peaks in electrical demand and may attempt to schedule charging events at non-peak times to avoid increases in utility costs as discussed in Reference 2.

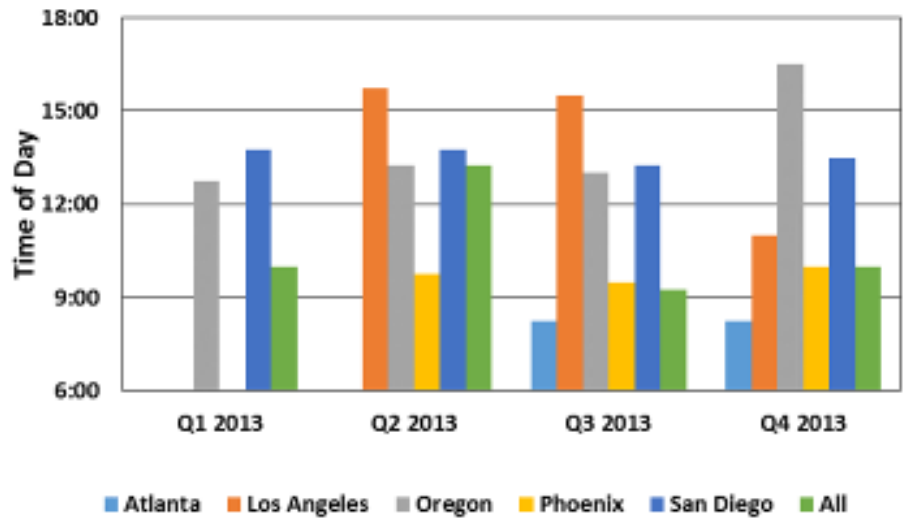

Figure 9. Private non-residential weekday peak median demand times by region.

\section{Energy Effects \\ Charging Behavior}

Charging availability is defined as the percent of EVSE that have a PEV connected in a geographic area. This is calculated by aggregating the data generated from all of Blink's onboard meters in the group of EVSEs being evaluated in the geographic area of interest over the timeframe desired. In Figures 10 and 11, the availability for each day of the quarter is overlaid on the time of day; therefore, the upper blue line indicates the maximum percent of EVSE with vehicles connected over the quarter, the red line shows minimum availability, and the black line shows median percentage of EVSE with vehicles connected over the quarter. The inner quartiles are shown as gray shaded areas. Data for weekdays and weekends are graphed separately. The following analysis uses the weekday median values for charging availability.

\section{Publicly Accessible Electric Vehicle Supply Equipment}

The shape of Figure 10 closely matches the shape of the corresponding charging demand of Figure 3. Users of publicly accessible EVSE expect their charge to commence immediately upon connecting to the EVSE. Thus, times of peak connectivity will coincide with the peak times identified above for demand, supporting the above suggestion that demand and the number of vehicles connected are, in fact, proportional. 


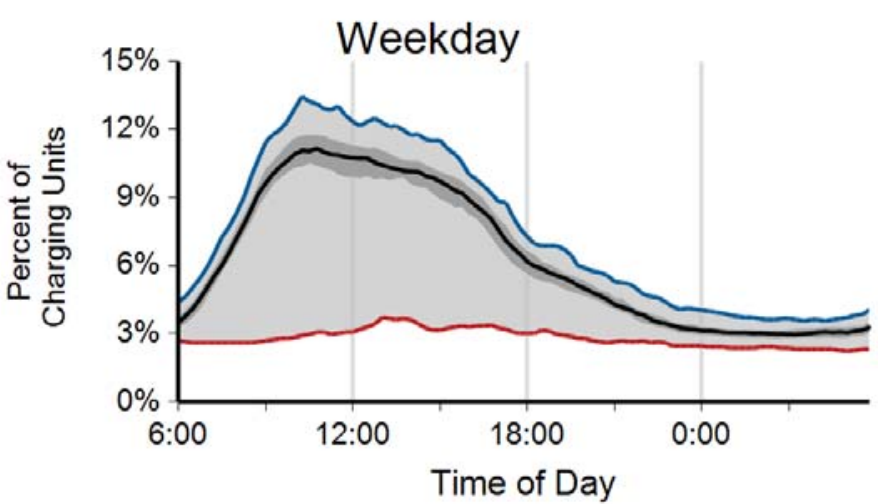

Figure 10. Charging availability for publicly accessible EVSE for all regions of The EV Project during the fourth quarter of 2013.

Figure 10 shows weekday aggregated charging availability over all EV Project regions during the fourth quarter of 2013.

The median value and inner quartile regions are closely grouped, indicating close agreement between the regions. Each region can expect PEVs to be connected to a peak of approximately $11 \%$ of the installed publicly accessible EVSE between 8 a.m. and 2 p.m., depending on regional specifics.

\section{Private Non-Residential Electric Vehicle Supply Equipment}

The charging availability for all regions of The EV Project in the fourth quarter of 2013 is shown in Figure 11.

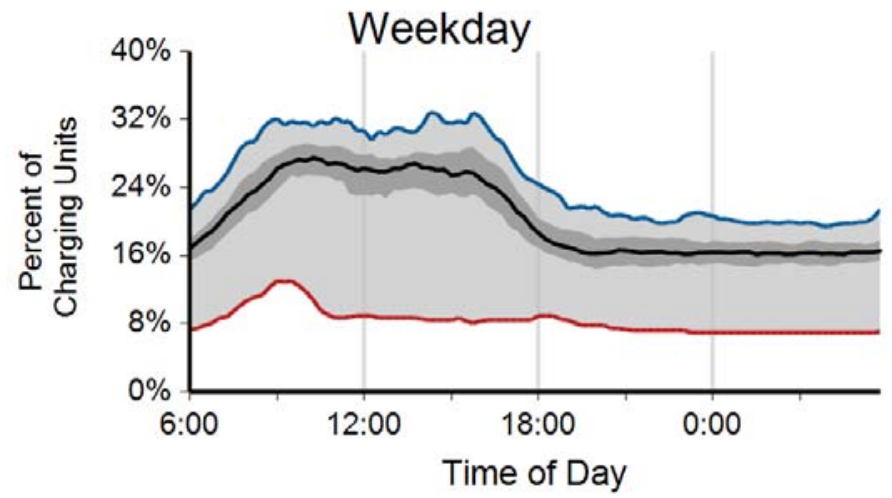

Figure 11. Charging availability for private non-residential EVSE for all regions of The EV Project during the fourth quarter of 2013.

As expected, this overall charging availability curve matches the shape of charging demand for private non-residential EVSE shown in Figure 8. As with publicly accessible EVSE, the PEV commences the charge immediately upon connecting to the EVSE.

\section{Energy Consumed}

\section{Publicly Accessible Electric Vehicle Supply Equipment}

Publicly accessible charge data collected by The EV Project were analyzed to identify the energy consumed over the time connected. Only connect events of 1 minute or longer in duration that actually delivered energy were considered. Connect periods greater than 1 day were excluded in the analysis. Figure 12 shows the results from the beginning of The EV Project through August 2013. The color differentiation shows the charging power. The blue data shows higher-level charge power with the maximum at approximately $7.4 \mathrm{~kW}$. The separation of red and blue occurs at approximately $3.7 \mathrm{~kW}$.

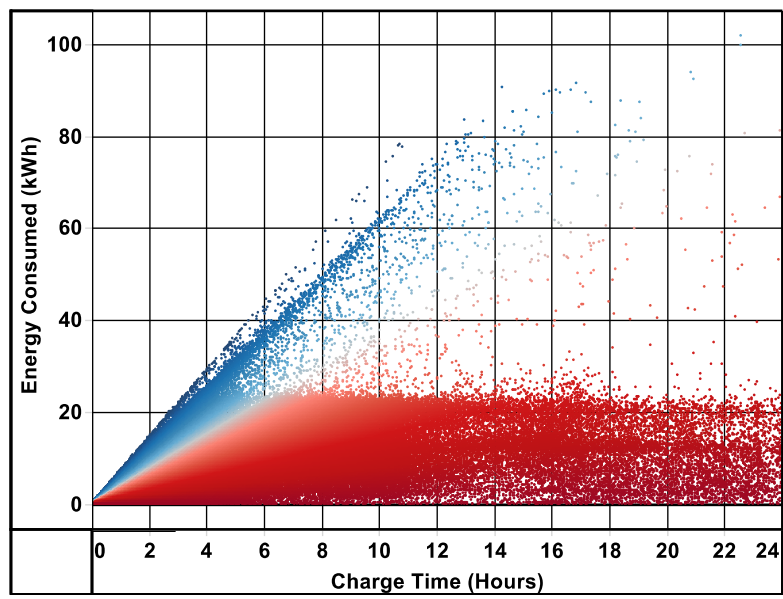

Figure 12. Publicly accessible AC Level 2 EVSE energy consumed versus charge time.

It is of interest to note that most of the red scatter points have maximum energy consumed upper values at approximately $22 \mathrm{kWh}$ and $13 \mathrm{kWh}$, which is near the capacities of the Leaf and Volt batteries.

The median connect time is 3 hours 3 minutes. The energy delivered in this time was a maximum of $22.1 \mathrm{kWh}$, a minimum of $0.08 \mathrm{kWh}$, and an average of $9.11 \mathrm{kWh}$. This is an average power of $3.04 \mathrm{~kW}$, which is near the maximum acceptance of most of The EV Project's vehicles.

As noted above, the maximum charge rate is determined by the PEV's onboard battery management system. Hence, for each time period noted in Figure 12, most charges occur at less than the maximum rated capability of the EVSE. Regardless of the charge rate, if the vehicle remains connected, the charge is likely to conclude near $100 \%$ state of charge. It is also clear that later model vehicles with higher charge rates and higher battery capacities have been periodically charging at these publicly accessible EVSE. 


\section{Private Non-Residential Electric Vehicle Supply Equipment}

Charge data from known fleet users were analyzed over the same time period noted above. As in previous analyses, only connect events of 1 minute or longer that actually delivered energy were considered, as well as connect times of 1 day or less. Figure 13 presents the results.

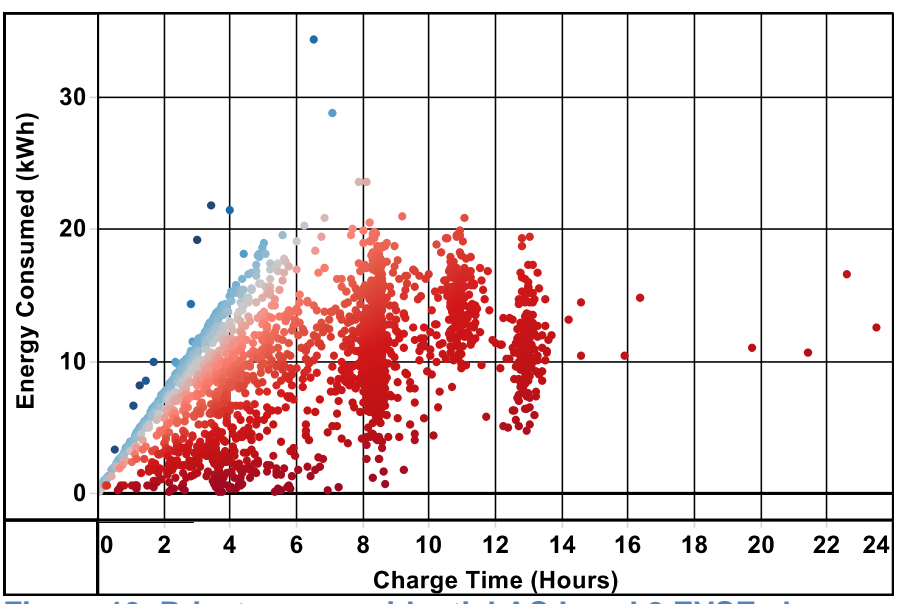

Figure 13. Private non-residential AC Level 2 EVSE charge energy versus charge time.

Again, the space between the red and blue scatter points shows a power delivery of approximately $3.7 \mathrm{~kW}$, indicating that few of the fleet vehicles were the later model PEVs with a higher power onboard charger. The median connect time is 7 hours 42 minutes during which an average of $12 \mathrm{kWh}$ is consumed by the vehicle.

\section{Conclusions}

During the term of The EV Project, the number of PEVs as a percent of the overall vehicle population was low. Although the number sold was over 100,000, they still represent less than $0.5 \%$ of all vehicles sold. Nevertheless, many electric utilities are involved in planning for an increasing adoption rate. In response to the question of "What is the impact on the electric grid?", some guidance can be provided by The EV Project.

PEV drivers establish charging habits that have been shown to be quite consistent over time. For the Chevrolet Volt in The EV Project, approximately 14\% of all charge events were away from home. For the Nissan Leaf, approximately $20 \%$ of all charge events were away from home. Because these two vehicles remained the most popular throughout The EV Project and drivers show consistency between regions, this behavior can be utilized for planning purposes.
For electric utilities, who may be concerned with charging power demand for publicly accessible EVSE, the median peak demand can be estimated at approximately $0.1 \mathrm{~kW}$ times the number of PEVs in the region and it is likely to occur between 8 a.m. and 2 p.m.

Private non-residential EVSE charging demand and times are highly dependent on the fleet or workplace environment and general characterization of peaks and times are not obvious.

When charging at publicly accessible EVSE, the median charge connect duration per PEV is approximately 3 hours and an average energy of $9.1 \mathrm{kWh}$ are consumed. When charging at fleet EVSE, the median charge connect duration per PEV is approximately $73 / 4$ hours and an average energy of $12 \mathrm{kWh}$ are consumed.

As PEV manufacturers increase the charge rate for their PEV batteries, charging will result in greater demand peaks. However, at the higher charge power, the charge duration will be shorter for the same total energy consumed by the PEV battery.

\section{About The EV Project}

The EV Project was the largest PEV infrastructure demonstration project in the world, equally funded by the United States Department of Energy (DOE) through the American Recovery and Reinvestment Act and private sector partners. The EV Project deployed over 12,000 AC Level 2 charging stations for residential and commercial use and over 100 dual-port direct current fast chargers in 17 U.S. regions. Approximately 8,300 Nissan LEAFs ${ }^{\mathrm{TM}}$, Chevrolet Volts, and Smart ForTwo Electric Drive vehicles were enrolled in the project.

Project participants gave written consent for EV Project researchers to collect and analyze data from their vehicles and/or charging units. Data collected from the vehicles and charging infrastructure represented almost 125 million miles of driving and 4 million charging events. The data collection phase of The EV Project ran from January 1, 2011, through December 31, 2013. Idaho National Laboratory is responsible for analyzing the data and publishing summary reports, technical papers, and lessons learned on vehicle and charging unit use.

\section{Company Profile}

Idaho National Laboratory is one of DOE's 10 multi-program national laboratories. The laboratory performs work in each of DOE's strategic goal areas: energy, national security, science, and the environment. Idaho National Laboratory is the nation's leading center for nuclear energy research and development. Day-to-day 
management and operation of the laboratory is the responsibility of Battelle Energy Alliance.

For more information, visit avt.inl.gov/evproject.shtml and avt.inl.gov/chargepoint.shtml.

\section{References}

${ }^{1}$ Characterize Clustering of Commercial Alternating Current Level 2 Electric Vehicle Supply Equipment, avt.inl.gov/evproject.shtml.

${ }^{2}$ What is the Impact of Utility Demand Charges on an Alternating Current Level 2 Electric Vehicle Supply Equipment Host?, avt.inl.gov/evproject.shtml.

${ }^{3}$ Characterize Plug-In Electric Vehicle Driver Away-FromHome Parking Behavior in San Diego, avt.inl.gov/evproject.shtml.

${ }^{4}$ http://insideevs.com/monthly-plug-in-sales-scorecard/.

5 ibid.

${ }^{6}$ Open El Load Profiles,

http://en.openei.org/datasets/files/961/pub/. 